\title{
OBSERVACIONES SOBRE EL ESPAÑOL EN SANTA BARBARA, CALIFORNIA*
}

Es evidente que así como parece no sólo inconveniente, sino equivocado referirse, por ejemplo, al español en América como si se tratara de un todo homogéneo que como tal se opusiera al español peninsular, tampoco puede hacerse eso con el español que hoy usan en Estados Unidos muchos millones de hablantes, pues consiste, como todo diasistema, de varios sistemas que llegan a diferir de manera sensible unos de otros. Por ende las frecuentes designaciones de población "hispanohablante", " "hispánica" o "de origen y ascendencia hispánica” en Estados Unidos son términos imprecisos y de ninguna forma sinónimos ${ }^{1}$. Sin embargo, en general suele calificarse a esta entidad llamada español de los Estados Unidos como rudimentaria, que supone un escaso uso de la lectura y la escritura; con una considerable diversidad léxica interna (y dialectal, en general); así como inserta en una habitual situación de bilingüismo que conduce necesariamente a la diglosia, en donde su uso queda relegado al ámbito familiar y a los niveles informales; y, finalmente, como otra peculiaridad, se menciona con frecuencia la "'mezcla" de idiomas (inglés y español) en que normalmente incurren los hablantes.

Es común clasificar en cuatro grupos mayores a los hispanohablantes de los Estados Unidos: mexicanos, puertorriqueños,

* Parte de este estudio, por lo que toca a Moreno de Alba, se pudo hacer gracias al apoyo de una beca Fulbright para investigación (verano de 1986), concedida por el Servicio Cultural e Informativo de los Estados Unidos de América.

${ }^{1}$ Esto resulta particularmente obvio cuando se pretende determinar la verdadera dimensión de la lengua española, como lengua de origen en ese país, y el grado de bilingüismo con el inglés que puede tener esa población (cfi. ERNESTO BARnACh-CAlbó, La lengua española en Estados Unidos, Oficina de Educación Iberoamericana, Madrid, 1980, p. 75). 
cubanos y peninsulares ${ }^{2}$. Las características que se señalan para el español de estos últimos son: si proceden del centro, un sistema fonológico de 18 fonemas, entre los cuales está ausente el palatal lateral $/ 1 /$; si el origen es andaluz, el sistema se reduce a 17 , por la eliminación de la interdental $\theta$, que se articula como [s], la aspiración de -s implosiva, confusión de líquidas, etcétera; casi todos conservan el uso de vosotros. Por lo que respecta al español cubano, la variedad estadounidense no difiere de manera significativa de la isleña debido a la reciente llegada del grupo a Estados Unidos (de 1959 en adelante); con el tiempo, sin embargo, no será sorprendente que se vean divergencias notables entre las dos modalidades, especialmente con relación a la interferencia con el inglés. El cubano exhibe debilitación y pérdida de vocales protónicas, sonorización de $k$, eliminación de - $d$ - en participios pasados, aspiración de $/ x /$, velarización de $-n$, debilitación, pérdida o aspiración de $-r$, aspiración, debilitación, asimilación, o pérdida de -s. El español puertorriqueño posee la mayoría de las peculiaridades del cubano, aunque habría que añadir, entre otras, la [R] velar y la asibilada, así como algunos vulgarismos morfológicos del tipo de póngamos, delen por denle, hadré por haré, que se documentan en amplias zonas hispanohablantes, y la inversión del verbo-pronombre en la interrogación ("¿Qué tú quieres?") )3. Lo que nos interesa destacar es el hecho de que el español mexicano-estadounidense, al que nos referiremos más adelante con mayor detalle, tiene rasgos predominantes diferentes de los que suelen asignarse a otros dialectos del español estadounidense. Queda así comprobada la variabilidad del español en esos territorios y la impropiedad de referirse a todas esas modalidades como "español de los Estados Unidos".

Por lo que concierne al español mexicano, se le ubica de manera predominante en el sur, más específicamente en el suroeste y suele atribuirse, como origen de los inmigrantes, el norte de México, parte del occidente y del Altiplano Central. Es frecuente clasifi-

${ }^{2}$ Así lo establece, por ejemplo, Daniel N. Cárdenas, Dominant Spanish dialects spoken in the United States, Educational Resources Information Center, Washington, 1970, p. 17. Hay que hacer notar, sin embargo, que en la última década ha habido un influjo numéricamente importante de grupos procedentes de otras naciones de América Latina, especialmente de Colombia, El Salvador, Guatemala, Nicaragua y Honduras.

${ }^{3}$ Como es fácil advertir, estamos simplificando en extremo los rasgos, ya de por sí muy resumidos, que ofrece Cárdenas (loc. cit.). 
carlo en cuatro zonas en los Estados Unidos: 1) Texas; 2) Nuevo México y sur de Colorado; 3) Arizona y 4) California ${ }^{4}$. En el español mexicano de Texas se observan, entre otros, los siguientes rasgos: asibilación esporádica de $/ \mathrm{rr} /$, aspiración de $/ \mathrm{x} /$, reducción de grupos consonánticos cultos en el nivel popular, eliminación en el habla coloquial, de - $d$ - (y, en menor grado, de - $y-$ y $-g-$; ruralismos como vivemos (por vivimos) y preferencia muy marcada de la perífrasis ir $a+$ infinitivo en lugar del futuro sintético. Es reconocido por todos el carácter arcaico del español de Nuevo México, debido en parte a un largo periodo de aislamiento, así como su vigencia y estabilidad que hacen, por ejemplo, que las leyes de las dos Cámaras se escriban en inglés y en español, lo que supone además que existe el derecho de defenderse judicialmente en cualquiera de las dos lenguas. Algunas de sus peculiaridades son: tendencia a la diptongación de los hiatos, aspiración de $f$-; eliminación de -y-; nasalización de las vocales; formas verbales rurales y arcaicas (truje, haiga, quedrá, ría [reía], vide, cáiba, créiba [caía, creía], etcétera); vocabulario igualmente anticuado: agora, ansí, escuro...5 ${ }^{5}$. La modalidad de la lengua española en Arizona es menos arcaica que en Nuevo México y pueden observarse ahí, aunque con mucho menor frecuencia, los rasgos anotados para ese dialecto.

Antes de referirnos al español californiano, conviene aclarar que el español mexicano ocupa también otras importantes áreas geográficas en los Estados Unidos. Baste señalar, como simples ejemplos, dos obras que tienen ese objeto de estudio. Así en Spanish in the U.S. setting. Beyond the Southwest ${ }^{6}$, se pueden leer algunos estudios que atienden variedades diferentes de las más frecuentemente analizadas. Por su parte Stanley M. Tsuzaki escri-

${ }^{4}$ Obviamente el mayor desarrollo se halla en las áreas fronterizas a lo largo del río Bravo y los límites con la Baja California, pero hay que notar que existen importantes conglomerados mexicanos en los estados de Illinois y $\mathrm{Mi}$ chigan. La zona urbana de Los Angeles es, por supuesto, donde más se concentra la población mexicana.

${ }^{5}$ Como se sabe, se cuenta con una excelente descripción de esta modalidad del español estadounidense en la obra de Aurelio M. Espinosa, Estudios sobre el español de Nuevo México, trad. y reelaboración con notas por Amado Alonso y Ángel Rosenblat, $B D H, 1$ (1930). Debe reconocerse, empero, que muy probablemente se han operado cambios importantes en el dialecto en los muchos años transcurridos desde la investigación de Espinosa.

${ }^{6}$ Lucía Elías-Olivares (ed.), National Clearinghouse for Bilingual Education, Rosslyn, 1983. 
bió un libro sobre una variedad del español mexicano en el norte de los Estados Unidos ${ }^{7}$.

Podría pensarse que el español que hoy se habla en California es una continuación de la lengua que hasta ahí llevaron los colonizadores españoles en el siglo xviII. Debe considerarse, sin embargo, que lo que acontece con el castellano de esa región hasta principios del siglo xx casi no guarda relación con el importante desarrollo que tendrá después, como efecto de lo que se ha llamado la época de las grandes inmigraciones. Es necesario tener en cuenta que a finales del siglo xix el español estaba ahí condenado a desaparecer y los movimientos migratorios de las primeras décadas del siglo actual vinieron en verdad a revitalizarlo. Como varios autores han señalado, ello se debe esencialmente a las copiosas inmigraciones de mexicanos y a su alta tasa de natalidad, aunque también han colaborado los desplazamientos de hispanohablantes que residían en los estados de Nuevo México, Arizona, Colorado y, quizá más abundantemente, de Texas ${ }^{8}$. Por otra parte, parece indudable que, antes de 1900, el sentimiento de mexicanidad entre los habitantes de ese extenso territorio estaba prácticamente ausente. Conviene recordar que recibieron con apática frialdad la noticia de la independencia de México, que los convertía por ende en ciudadanos mexicanos. Y puede decirse sin hipérbole que, antes de que se acostumbraran a su nuevo estado de mexicanidad, formaban ya parte de los Estados Unidos. La historia explica que los veinticinco escasos años que California perteneció a México casi no sirvieron para fomentar un sentimiento nacionalista, pues parece ser que no había voluntad de los californios para hacerse mexicanos, a lo que debe sumarse el lamen-

7 S. M. TSUZAKI, English influence in the phonology and morphology of the Spanish spoken in the Mexican colony in Detroit, Michigan, Ph. D. dissertation, University of Michigan, Ann Arbor, 1963. Vale la pena transcribir algunas de sus conclusiones: 1) las interferencias del inglés con el español no se deben a desconocimientos de éste; 2) modifican muy moderadamente la estructura del español; 3) hay una relación inversa entre aculturación y uso del español; 4) por el contrario, hay una estrecha relación entre aculturación e incidencia de préstamos; 5) es muy dudoso que el inglés llegue a reemplazar totalmente al español (hay monolingües, continúa la inmigración, etcétera), pp. 63-64.

${ }^{8}$ Para estos y otros datos resulta útil la consulta del libro de ANTonio Blanco, La lengua española en la historia de California, Cultura Hispánica, Madrid, 1971. El aspecto propiamente filológico o lingüístico es muy poco técnico; sin embargo, para un acercamiento histórico al asunto, proporciona abundante información. 
table descuido del gobierno de México para estos territorios y la poca calidad de los gobernadores mexicanos, que en ocasiones se hicieron merecedores de su expulsión de California. Por otra parte, si la independencia de México sucedió en 1821, en California vino a influir realmente sólo unos diez años después, al llegar la expedición Híjar-Padrés, pues se trataba de gente más culta y en número más importante que las que la precedieron y, naturalmente, tuvo que ver de manera destacada en el proceso de mexicanización.

Es probable, aunque aún discutible, que en el español primitivo de California, el de finales del siglo xviII y principios del xix, haya influido más la lengua de los soldados presidiales que la de los misioneros, con un más alto nivel cultural, aunque debe reconocerse que aun aquéllos eran realmente muy pocos: hacia 1764 había sólo 1271 soldados (incluyendo oficiales) y tenían el encargo de defender un territorio de 3500 kilómetros, en el cual estaban dispersos 23 presidios o establecimientos militares. Y si se pasa al año 1823, se verá que eran unas cuantas las familias que se habían podido llevar de México, unas treinta aproximadamente, cuando el número de habitantes era de 3270 , sin contar los indios aborígenes. El resto eran españoles y, particularmente, soldados. Según Duflot de Mofras, en 1824 había: 4000 descendientes de europeos (con toda probabilidad predominantemente españoles), 360 estadounidenses, 300 ingleses, escoceses e irlandeses, 80 españoles, 80 franceses, 90 alemanes, italianos, portugueses e isleños de varias procedencias, y 90 colonos mexicanos ${ }^{9}$.

Todo lo anterior permite pensar que, aún durante la época mexicana, California era una pequeña colonia española que cultural y lingüísticamente daba lugar a modalidades muy diversas de las que entonces se estilaban en México. Ya se sabe que inmediatamente después, a partir de 1842, los norteamericanos empezarán a afluir de manera impresionante (recuérdese la fiebre del oro), de tal manera que, por ejemplo, de 1842 a 1846 llegan a igualar a la anterior población hispanohablante ${ }^{10}$. Naturalmente que la aculturación de éstos fue inmediata. El historiador Bancroft escribía a fines del siglo xix: "no existía una comunidad fuerte en ningún sentido, ni moral, ni físico, ni político. Por eso,

${ }^{9}$ Citado en Blanco, op. cit., p. 125.

${ }^{10}$ Aunque debe aclararse que la parte sur del territorio, que incluye Santa Barbara y San Diego, recibió más tardíamente los contingentes importantes de norteamericanos y preservó un tipo de vida más apegado a los hábitos españoles. 
así como los salvajes [sic] se esfumaron ante la superioridad de los mexicanos, así se esfumaron éstos ante la superioridad de los americanos" $"$. Esto viene a comprobarse en los censos posteriores: si hacia 1860, entre 380000 habitantes se señala sólo la existencia de 9200 mexicanos, en el de 1880 sólo habrá 8600 entre 864700 pobladores. Como se comprenderá, hacia esa época, los antiguos californios estaban ya perfectamente adaptados a la nueva cultura; los mexicanos (y, obviamente, los indios) fueron perseguidos y discriminados. El resultado de esa actitud represiva e intolerante, que de cierta manera perdura hasta nuestros días, es que hacia finales del siglo apenas si se hablaba un poco de español en toda el área y este poco estaba además destinado a desaparecer casi del todo. Serán, como ya se notó, las migraciones de los mexicanos, en las primeras décadas del siglo xx, de manera prácticamente constante ${ }^{12}$ y creciente hasta nuestros días, las que explican hoy el florecimiento y pujanza del español de California, aun cuando hay una marcada oposición - hasta oficial - al bilingüismo ${ }^{13}$. Debemos suponer que, de interrumpirse esa corriente migratoria, especialmente en vista de la nueva ley de inmigración que entra en vigencia en mayo de 1987, volvería la amenaza de extinción de la lengua española a mediano plazo.

La influencia del español mexicano a finales del siglo xviII y principios del xix debió haber sido de muy poca importancia ${ }^{14}$. Sin embargo, de este periodo datan algunos indigenismos léxicos (nahuatlismos, generalmente), muchos de los cuales persisten hasta hoy: camote, ocote, pozolera, tepetate, totopo...15. Algunos otros me-

11 Blanco, op. cit., p. 131.

12 Aunque debe señalarse que la inmigración tanto legal como ilegal se redujo sustancialmente, primero por la gran depresión económica de los años 1930-1933 y después por las oportunidades de trabajo que trajo consigo la política económica de Lázaro Cárdenas. Cf. José G. Moreno de AlbA, "OObservaciones sobre el español en la frontera norte de México", en La frontera del norte. Integración y desarrollo, R. González Salazar (ed.), El Colegio de México, México, 1981, pp. 85-94.

13 En noviembre de 1986, los californianos aprobaron en las urnas una medida legal que declara el inglés la lengua oficial del estado y que limita notablemente la posibilidad de emplear el español ( $y$ otras lenguas) en contextos oficiales y gubernamentales. Paralelamente, se han reducido drásticamente los fondos destinados a la educación bilingüe.

14 Sobre el español de esta época escribe Blanco: "Hemos encontrado pocos mejicanismos y en la gran variedad de términos referentes a los vaqueros creemos que la mayoría son de origen californiano" (op. cit., p. 160).

15 Aunque otros indigenismos registrados por Blanco (pp. 163 y ss.) re- 
xicanismos deben situarse ya en la época propiamente mexicana (entre 1823 y 1846): achichinque, comal, jacal, mecate, petaca, molcajete, chapopote... Uno de los rasgos predominantes de la influencia mexicana por esos años es, a juicio de Blanco "una abundantísima cantidad de palabras ya típicas en el español de México, lo mismo que una construcción gramatical diferente, en la que intervienen no pocos vulgarismos que antes no habíamos hallado" (p. 321). Se refiere, por ejemplo, a dislocaciones acentuales de vocales, diptongaciones, epéntesis, cambios analógicos de verbos y muchos otros fenómenos rurales o vulgares. También se transcriben vocablos que, seguimos resumiendo a Blanco (p. 341), parecen proceder de etapas anteriores del desarrollo del español: cirgüela, aigre, catota (canica), cholo (soldado), cosijoso (insistente), fifi (elegante), fifirifi (flaco), tuturusco (borracho)... Y ya en el español californiano del siglo XIX se documentan anglicismos del tipo espauda (yeast powder), basqueta (basket), guara (water), etcétera.

La lengua española en California, quizá más que la de las otras zonas de los Estados Unidos, se caracteriza, según varios estudiosos, entre ellos Blanco, por el alto grado de rusticismos, que se debe, entre otros factores, a un sustrato de hablantes de nivel sociocultural bajo: "Los emigrantes que en aluvión llegaron a principios del siglo $\mathrm{xx}$, casi todos indigentes, "sobrantes" modestos de las más apartadas regiones del país (el diez por ciento de la población total de México) [. . . ] traían consigo también una lengua rústica y llena de provincialismos además de muchos términos jergales y de germanía"' (p. 254). No cabe duda de que las subsiguientes inmigraciones, incluyendo las que hoy siguen engrosando el número de mexicanos en California, tienen características sociales, económicas y culturales semejantes.

Por otra parte, la modalidad del español californiano no parece equivalente al nuevomexicano, el que describe Espinosa (cf. nota 5) y que se quedó en casi completo aislamiento. Es muy probable que hacia 1840 sí hubiera muchas afinidades entre estos dos dialectos, pero el californiano, como ya se dijo, prácticamente desapareció a finales del siglo xix y el que hoy se habla tiene como base el de los mexicanos que comenzaron a llegar durante las primeras décadas del siglo $\mathrm{xx}$ y las siguientes inmigraciones ${ }^{16}$.

sultan hoy poco conocidos aun para el hablante mexicano medio: cacaste, chancaca, niscayote, tepetomate...

${ }^{16}$ Se necesitaría asimismo un buen número de pruebas para aceptar la 
No hay un estudio que pretenda describir, en su totalidad, el español californiano. Sí existen, empero, importantes estudios sobre variedades particulares, especialmente la de Los Angeles ${ }^{17}$. Si se consulta la bibliografía que publicaron Richard V. Teschner, Garland D. Bills y Jerry R. Craddock ${ }^{18}$, se observará que en general las investigaciones sobre el español de los Estados Unidos (no sólo el de California) tienen un enfoque socioligüístico y casi no las hay que tengan por objeto una descripción pormenorizada de la fonética, la gramática y el léxico, a la manera de la tradicional dialectología, a nuestro entender indispensable como base sobre la cual puedan concebirse otro tipo de acercamientos al fenómeno lingüístico.

Los rasgos que proporciona Cárdenas sobre el español californiano son sumamente pobres y superficiales: existencia de palabras y frases inglesas intercaladas en la cadena hablada (probablemente se refiera al fenómeno que ahora se conoce como cambio de código - code switching-, cf. infra p. 196); modificaciones en los patrones entonativos; presencia de algunas peculiaridades que dejó el pachuco de los años treinta y cuarenta; y, en general, un estado de bilingüismo con el inglés que el autor califica de "solución diferente y digna"' (p. 27).

En 1850 la población de California era de 93000 habitantes, que representaban un $0.4 \%$ de la población total del país. En 1985 el estado cuenta con 25857500 habitantes, que constituyen el $10.8 \%$ del total nacional ${ }^{19}$. Si las cifras relativas a la población general son fidedignas, no se puede decir lo mismo de las esta-

hipótesis de CÁRDEnas (op. cit., p. 27) en el sentido de que el español de California viene a ser una extensión del de Arizona.

${ }^{17}$ Cf., por ejemplo, los artículos de Robert N. Phillips, "The segmental phonology of Los Angeles Spantsh", en J. DONALd Bowen y Jacob ORN. STEIN (eds.), Studies in Southwest Spanish, Newbury House-Cambridge University Press, Rowley, 1976, pp. 74-92; "Influence of English /b/ in Los Angeles Spanish", in Jon Amastae y Lucía Elías-Olivares (eds.), Spanish in the United States. Sociolinguistic aspects, Cambridge University Press, New YorkMelbourne, 1982, pp. 71-78; y su tesis, "Los Angeles Spanish: A descriptive analysis", University of Wisconsin, Madison, 1967.

${ }^{18}$ Spanish and English of the United States hispanos: A critical, annotated, linguistic bibliography, Center for Applied Linguistics, Arlington, 1975.

${ }^{19}$ Los datos relativos a la población nacional, estatal y de los varios condados derivan de varias publicaciones oficiales que emanan del Censo Oficial de 1980. Los datos resumidos aquí provienen de California almanac. 1986-1987 edition, Sacramento, 1985; California county fact book, Sacramento, 1984. 
dísticas referentes a la población hispánica, sea hispanohablante o anglófona. El censo americano se empeña en emplear clasificaciones genéricas (Spanish American), y decididamente erróneas (Spanish origin), que dificultan el proceso de obtener una visión medianamente clara de la distribución y tipología de la población hispánica. Sin embargo, es indudable que la población hispánica, por genérica que sea la clasificación, es de origen mexicano, por lo menos en California y en gran parte del suroeste. Según el censo de 1980, el condado de Santa Barbara tenía 298694 habitantes, de los cuales 55356 se clasifican como de origen español (Spanish origin); esta cifra corresponde al $18.5 \%$ de la población total y no difiere notablemente del promedio estatal. Si bien hay condados con un porcentaje notablemente más alto de población hispánica (Imperial, 55.8; San Benito, 45.7; Fresno, 29.3, para citar sólo algunos), el condado de Santa Barbara se sitúa muy cerca del promedio estatal, que es de un $19.2 \%$ (4 544331 ).

Una población mexicano-americana del $20 \%$, a pesar de ser significativa, no parece étnicamente determinante, pero hay que recordar que los censos no reflejan, en general, los grandes números de trabajadores indocumentados que, con o sin familia, se suman a las filas de los mexicanos "legales". Es extremadamente difícil calcular el número de mexicanos indocumentados residentes en California, dado el continuo flujo y renovación de la fuerza laboral. Pero sería erróneo tratar a esta porción de la población como marginal e irrelevante para efectos de nuestro estudio. Éste es el segmento que ha estado nutriendo y sosteniendo el español tanto en California como en el suroeste en general y que difiere del grueso de los "hispanos" sólo por su calidad migratoria. No será superfluo recordar aquí que la nueva ley de inmigración de los Estados Unidos legalizará la presencia de todo trabajador y familiar que pueda documentar su estancia en el país a partir de $1982^{20}$. Reconociendo la necesidad de ajustar las cifras anteriores para reflejar lo antedicho, no sería aventurado hablar de un promedio estatal del 30 al $40 \%$ de mexicanos en la población total. Si consideramos que la tasa de crecimiento demo-

${ }^{20}$ En patente paradoja, la nueva ley exije prueba de residencia justamente a aquellos que durante años se han visto obligados a esconderse y a borrar sus huellas documentales para no ser repatriados. Es asimismo interesante observar cómo el gobierno estadounidense no está en grado de calcular cuántos serán los amnistiados. Se habla de dos a cinco millones de personas legalizables; esa cifra, según algunos, apunta a posiblemente diez millones de indocumentados, legalizables o no. 
gráfico de este segmento es cinco veces superior a la del grupo dominante, saltará a la vista que la actual minoría notable se convertirá pronto en mayoría sumamente visible.

Sobre el español de Santa Barbara en particular no existe publicado estudio alguno. En cuanto al carácter de comunidad lingüística que consideramos indispensable para convertirla en sujeto de investigación dialectal, no cabe duda que encaja dentro de parámetros establecidos. Además de contar, como acabamos de señalar, con una abundante población hispanohablante, ésta se concentra en dos secciones fácilmente identificables en la ciudad (la sección este y la noroeste); la existencia de muchos programas sociales y educativos destinados a una población no anglohablante o bilingüe es también indicio de la vigencia y vitalidad de la comunidad. En el terreno de la observación directa, hasta el visitante más casual notaría la presencia de este grupo, pues se oye el español en cualquier parte de la ciudad y en cualquier circunstancia. Si bien es obvio que el inglés es la lengua mayoritaria y de más prestigio, el uso del español rebasa el ámbito hogareño e invade las zonas públicas donde coexiste y compite con el inglés. Y también hay que recordar que el empleo del español no supone, en un mismo individuo, falta de dominio del inglés. El alto número de bilingües apunta y evidencia la continuidad de una comunidad hispanohablante.

A nuestro entender, mucha razón tiene Anthony G. Loza$n o^{21}$, cuando precisamente en relación con el estudio de las variedades del español estadounidense explica la necesidad de descripciones que contengan las principales características o rasgos del dialecto, de manera general y esquemática, antes de emprender estudios minuciosos sobre una particular realización fonética o forma sintáctica, pues se corre el riesgo de que tales descripciones, sumanente detalladas, impidan en cierta forma tener una clara idea del dialecto en su totalidad. En las páginas que siguen se pretende precisamente presentar los aspectos predominantes (fonéticos, gramaticales y léxicos) del español en Santa Barbara, como un primer y necesario acercamiento que facilite, en su caso, descripciones futuras más minuciosas y particulares. Los datos proceden del análisis de conversaciones grabadas magnetofónicamente. En ellas intervienen siempre sujetos que o bien nacieron en Santa Barbara (la mayoría) o bien han vivido ahí la mayor parte

21 "Mantenimiento del español: enfoque y crítica", en Spanish in the United States setting. Beyond the Southwest, pp. 252-256. 
de su vida y allí radican al momento de la encuesta. Los padres de buena parte de los encuestados son mexicanos de nacimiento, aunque hay casos en los que se tiene que ir hasta los abuelos para encontrar a los ancestros mexicanos. Todos los sujetos de la muestra son bilingües. Casi todos hacen uso del español en situaciones de comunicación familiar o entre amigos, aunque no faltan personas que, por razones de carácter laboral, hacen uso del español en otras circunstancias. La comunicación con el cónyuge es normalmente en español, así como con los padres o abuelos. Por lo contrario, no en todos los casos se usa el español para hablar con los hijos; varios de los sujetos declararon que el tratamiento con sus hijos era en inglés o, en no pocos casos, mixto: de padres a hijos en español y de hijos a padres en inglés. A este propósito convendría recordar que el debilitamiento del español en el seno de la familia es uno de los principales argumentos que pueden esgrimirse para hacer depender de la inmigración ininterrumpida la sobrevivencia del español en California. Es de suponerse que de manera paulatina las nuevas generaciones se expresarán más y más en inglés a costa de español. Es bastante frecuente que los nietos de abuelos mexicanos e hijos de padres nacidos ya en los Estados Unidos empleen el español de manera asistemática y con muchos errores. Si no disminuye el proceso de absorción y aculturación, en muy pocos años esta población no tendrá ni siquiera un conocimiento pasivo del español. Se puede observar ya, por ejemplo, que en una familia de varios hijos son precisamente los menores los que menos conservan el uso del español. Pero tampoco faltan excepciones que apuntan a la existencia de una acendrada tradición que transmite de padres a hijos la lengua de los ancestros. Existen también numerosas familias en las que el español se mantiene vivo a pesar de las presiones del inglés en una sociedad que tradicionalmente le ha pedido al inmigrado que se despoje de su lengua y cultura y que se asimile al resto de la población. En estas familias hay una clara conciencia de que el español no es una disyuntiva sino una opción complementaria que enriquece y mantiene viva una identidad étnica, al mismo tiempo que no interfiere con la integración a la cultura mayoritaria.

Los 21 sujetos que participaron en las conversaciones grabadas se agrupan de la siguiente forma: 11 mujeres y 10 hombres; 5 de la primera generación ${ }^{22}, 9$ de la segunda y 7 de la tercera.

${ }^{22}$ De conformidad con criterios aplicados anteriormente, de cualquier forma arbitrarios, consideramos primera generación hasta los 30 años; segunda, 
OBSERVACIONES FONÉTICAS

\section{Vocalismo}

El sistema vocálico del español en Santa Barbara se mantiene íntegro y no parece estar en peligro de sufrir cambios radicales; las variantes que se dan a continuación son atribuibles, en algunos casos, al contacto con el inglés y, en otros, se ajustan a rasgos y tendencias del español general y a fenómenos documentados en otros dialectos. Los fenómenos vocálicos peculiares en el español de Santa Barbara son cuatro: la diptongación de hiatos; el cierre de /e/ y /o/ (particularmente en posición final); la abertura de vocales (en especial de /i/ y /u/ en diversas posiciones); y la velarización de /a/ ([a]]). Para dar una idea sobre la frecuencia de cada uno de los fenómenos en relación con los otros tres, podría asignarse, en una escala que vaya del 0 al 10 , un 6 a la diptongación, 3 tanto al cierre como a la abertura y 1 a la velarización. En otras palabras podría decirse que esta última es de carácter esporádico, que los fenómenos de abertura y cierre son poco frecuentes y que la diptongación viene a ser el rasgo vocálico sobresaliente en el dialecto.

La diptongación más frecuente es la que no conlleva cambio acentual sino sólo una semivocalización (o semiconsonantización) de una vocal, en particular de la /e/ de ea, ae: atrae > [atrái], teatro $>$ [tjátro], voltearon $>$ [boltjáron], recreación $>$ [rekrjasjón], empleado $>$ [empljád/o]. Se produce también en fonética sintáctica: me asociaba $>$ [mjasosját/a], de una $>$ [djúna], de aquí $>$ [djakí], me amarga $>$ [mjamárga]. No faltan casos de traslación acentual: oído > [óiđo], caído > [káiđo] y de metátesis: ciudad > [swiđáa así como de diptongación de vocales y no de hiatos: $d i$ jera $>[\text { dixjéra }]^{23}$.

El cierre vocálico es frecuente en fin de palabra: estuve, años, nueve, unidos > [estúbe, áños, nwébẹ, uníđọs]; aunque también puede aparecer en otras posiciones, posiblemente por metafonía:

de 31 a 50 y tercera, de 51 en adelante. Cf. Giorgio Perissinotro, "Hacia una fonética del español hablado en San Antonio, Texas", $A L M, 14$ (1976), pp. 56-57.

${ }^{23}$ Algunas monoptongaciones pueden quizá explicarse mejor como arcaísmos, ruralismos o, si se quiere, como fosilizaciones léxico-gramaticales: quieren $>$ [kéren]. 
tenía, llovía > [tẹnía, yọtía]. En otras ocasiones el cierre de vocales puede verse como asunto de morfología verbal arcaizante o rural: seguí, serví, decia, tenía, vestía > [sigí, sirbí, disía, tẹnía, bistía].

La abertura vocálica se documenta principalmente en posición pretónica o tónica: latinas, pudiera, principio, subi, puro, agricultura, veces, ocupación > [latịnas, pụđjéra, prịnsipjo, sụtí, pứro, agrikụltúra, bę́ses, okupasjón]. Asimismo no pocos casos de abertura pueden ser explicados también desde una perspectiva de morfología verbal: salimos, vivimos > [salémos, bitiémos].

Esporádicamente, pero con mayor frecuencia que la que se registra en el habla media de México, por ejemplo24, aparece en Santa Barbara el fenómeno del atrasamiento o velarización de /a/ ([a]), predominantemente ante $-l$, consonante que suele también, en tales casos y quizá por interferencia con la pronunciación inglesa, articularse palatalizada o atrasada en relación con su habitual punto de articulación (alveolar) español: animales, capital, nor-

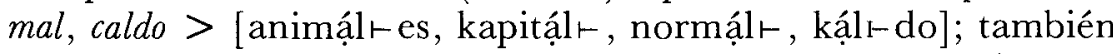
en: clases, mandaron, dejaron $>$ [klạ́ses, mandạ́ron, dexạaron].

\section{Consonantismo}

Se procederá aquí también presentando, en orden decreciente, los fenómenos que se juzgan más representativos. Sin embargo creemos que puede encontrarse una característica general que comprende prácticamente todo el consonantismo peculiar del español de Santa Barbara. Nos referimos a la debilitación o relajamiento, que se manifiesta de diversas maneras en cada fonema, como podrá apreciarse en los resúmenes que siguen.

Las vibrantes. Tanto la vibrante múltiple cuanto la simple (explosiva e implosiva, sobre todo esta última) manifiéstan un alto grado de relajación en su articulación. Parece ser que es la vibrante simple en posición implosiva la que resulta más evidentemente debilitada. La - $r$ se presenta con cuatro alófonos predominantes: 1) fricativa con cierto grado de retroflexión $[r]$, que se registra

${ }^{24}$ Con la que tácitamente estamos comparando las realizaciones fonéticas de Santa Barbara (cf. Giorgio Perissinotro, Fonologia del español hablado en la ciudad de México. Ensayo de un método sociolingüístico, El Colegio de México, México, 1975). 
aproximadamente en un $31 \%$ de los casos; 2) la simplemente fricativa (no vibrante) $[\mathrm{r}$ ], que se da en un $28 \%$; 3 ) la variante asibilada [r. ], con una frecuencia del $23 \%$; 4) la vibrante simple $[\mathrm{r}]$, que resulta el alófono menos frecuente, con sólo un $18 \%$ de apariciones. Algunos ejemplos de $[\underset{\wedge}{\mathrm{r}}],[\mathrm{r}]$ y $[\stackrel{\mathrm{r}}{\mathrm{r}}]$ implosivas: ayudarlos, trabajar, partes, prepararse; sostener, tarde, terminé, porque; mayor, persona, pelear > [ayudárlos, trabahạar, pártes, preparárse; sostenéf, táłde, terminé, półke; may $\perp$ ór, peřsóna, peljár̆]. Quizá un análisis mucho más minucioso permitiría encontrar con mayor precisión los entornos fonéticos que favorecen cada alófono; así por ejemplo puede decirse que el retroflejo se da con mayor frecuencia ante/t/ y que el asibilado es normal ante pausa y en contacto con /s/. Las mujeres asibilan, según nuestros materiales, sólo un poco más que los hombres, a diferencia de otros dialectos del español en que la diferencia es mucho más acusada ${ }^{25}$.

La vibrante múltiple $/ \bar{r} /$ da también muestras de falta de tensión articulatoria pero en menor grado que la -r implosiva. Convendría distinguir cinco alófonos de mayor incidencia: 1) la vibrante múltiple $[\overline{\mathbf{r}}]$ que se escucha en un $36 \%$ de los casos; 2) la variante fricativa larga no vibrante $[\overline{\mathrm{F}}]$, que tiene una frecuencia del orden del $21 \%$; 3) la asibilada larga $\left[\frac{\vee}{\mathrm{r}}\right]$, que se registra en un $24 \%$ de los casos; 4) el alófono vibrante simple [r], que se oye en un $11 \%$ de las apariciones de $/ \overline{\mathrm{r}} / ; 5$ ) la variante retrofleja larga $[\overline{\mathrm{r}}]$, que documentamos en sólo un $8 \%$. Si se suman las frecuencias de los últimos cuatro alófonos $\left[\overline{\mathrm{r}}, \frac{\mathrm{v}}{\mathrm{r}}, \mathrm{r}, \overline{\mathrm{r}}\right]$, que en ạlguna forma constituyen debilitamiento articulatorio de $/ \overline{\mathrm{r}} /$, se observará que la $/ \bar{r} /$ del español estándar aparece en franca desventaja (36/64) frente a las variantes que suponen menor tensión. Ejemplos de $[\bar{f}, \overline{\mathrm{r}}, \mathrm{r}, \overline{\mathrm{r}}]$ : arriba, guerra, recibi, roto, repararlo, la ra$z a$, no regreso, guerra, muy rápido, desarrollaron, me retiré $>[a \overline{\mathbf{f}} \mathbf{i} \mathrm{ba}$,

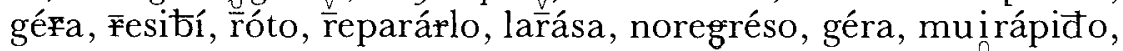
desar̃ ojáron, mer̃etiré].

Finalmente, algunas consideraciones sobre la vibrante simple intervocálica $-r$-. Sin duda la realización más normal resultó precisamente la que conserva la vibración [r], con un $62 \%$. Sin embargo no son de poco interés los alófonos relajados como [r], fricativo, con un promedio de uso del 16\%; y tanto el retroflejo $[\mathrm{r}]$

${ }^{25}$ Cf., por ejemplo, José G. Moreno de Alba, "Frecuencias de asibilación de /r/ y /rr/ en México", NRFH, 21 (1972), 363-370; y Giorgio PerissiNotтo, "Distribución demográfica de la asibilación de vibrantes en el habla de la ciudad de México", ibid., 71-79. 
cuanto uno que podría denominarse muy relajado [r], con frecuencias, cada uno, del 11\%: por eso, mira, Arizona, pero, derecho, lugares [poféso, míra, arisóna, péro, deréso, lugáres].

Otros fenómenos relacionados con las vibrantes son sólo de carácter esporádico en el dialecto de Santa Barbara, como la asibilación en los grupos $t r, p r$ [třr, pry] o la retroflexión en esos mismos grupos debido posiblemente a la influencia de la fonética inglesa: tres, trabajo, producción, precio [trés, traちáxo, prođugsjón] ${ }^{26}$.

El fonema $\mid y /$. Las articulaciones más frecuentes del fonema /y/ en el español de Santa Barbara vienen a ser una prueba más de la tendencia al consonantismo débil. Es fácil advertir, ante todo, un marcado polimorfismo (ya señalado para el caso de las vibrantes y que, en definitiva, parece propio de casi todos los fonemas y todos los idiolectos). Al menos es posible distinguir cuatro alófonos de la palatal central sonora: 1) [y], conservada más o menos tensa; 2) $[\mathrm{y} \perp]$, alófono que denota ya un perceptible aflojamiento de la articulación, aunque no se pierde aún el carácter consonántico del fonema; 3) [j] articulación de /y/ como semiconsonante, formando diptongo con la vocal contigua; 4) el cero fonético [Ø] o falta total de articulación. De conformidad con los materiales que analizamos, las frecuencias pueden expresarse por los siguientes porcentajes:

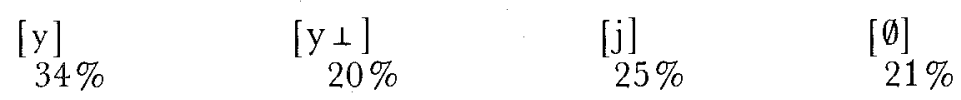

Obsérvese nuevamente que la suma de los alófonos debilitados $(66 \%)$ es casi el doble que los registros que obtuvo la articulación plenamente consonántica (34\%). Resulta evidente que hay ciertos entornos que favorecen la debilitación de $/ \mathrm{y} /$ : se ve, por ejemplo, que con frecuencia ésta se pierde totalmente en contacto con /i/ anterior tónica: chiquilla, milla, cepillar, sillas, tortilla > [šikía, mía, sepiár, sías, tortías], articulaciones que hacen pensar en la variedad norteña del español de México; aunque hay

${ }^{26}$ En el estudio de Phillips ("The segmental phonology..."), en lo que corresponde a vibrantes se señala: 1) que la /r/ tiene, en el español de Los Angeles, dos pronunciaciones básicas: la vibración múltiple (sonora, ápico-alveolar) y otra $[\mathrm{I}$ ], "which is voiced, non apical alveolar groove fricative, with a small amount of retroflection of the tongue" (p. 78); 2) la existencia de una [r], en pocos casos, que equivale a la inglesa (p. 81);3) entre los diversos alófonos de la $r$ implosiva ante pausa, sobresale el vibrante simple $[\mathrm{r}]$ (p. 81). 
otros vocablos que en muchos sujetos parecen ya fosilizados con pérdida de $/ y /$, en especial los pronombres ellos, ellas, que en muchas ocasiones se articulan [éos, éas]. Algunos ejemplos más de debilitaciones de /y/: calle, mayo, caballos, calle, se llama, allá, mejillas, maravillas, millares, mayor, se aye $>$ [káe, májo, kaちájos, káje,

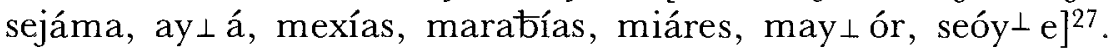
Se registran contracorriente, unos notables casos de epéntesis de [y]: la universidad $>$ [layunitersiçáđ] , correo $>$ [koréyo], atraer $>$ [atrayér].

El fonema $/ x /$. Son tres los alófonos de $/ x /$ que fácilmente pueden percibirse en el español de Santa Barbara: 1) la articulación consonántica velar fricativa sorda (aunque menos tensa que, por ejemplo, la /x/madrileña), a la que corresponde aproximadamente un $37 \%$ de las apariciones; 2) una pronunciación intermedia, entre la $[\mathrm{x}]$ y la [h], que transcribimos como [ $\left.{ }_{\mathrm{x}}^{\mathrm{h}}\right]$, en la cual ya hay un grado considerable de relajación, pero todavía existe alguna fricación velar; en nuestros informantes se documentó un $24 \%$ de los casos de /x/ con esta articulación; 3) una aspiración laríngea $[\mathrm{h}]$, que viene a ser el grado máximo de relajación de la consonante, y que fue escuchada en un $39 \%$ de los casos. Es importante destacar que la aspiración es en Santa Barbara el alófono más frecuente de $/ \mathrm{x} /$; si se le añaden las articulaciones de relajación media $[\stackrel{\mathrm{h}}{\mathrm{x}}]$, es claro que estamos ante un evidente fenómeno de consonantismo debilitado ${ }^{28}$. Los siguientes son ejemplos característicos de articulaciones relajadas: México, trabajo, jardín, gente, emergencia, lujo, ejemplo, manejando, se juntó $>$ [méhiko, tra-bá-

27 Varios autores se han referido al fenómeno de la debilitación articulatoria de $/ y /$, tanto en ciertas hablas mexicanas cuanto en algunos dialectos del español estadounidense. Entre otros, cfi. JuAn M. LOPE BLANCH, "Sobre el rehilamiento de 11/y en México", en Estudios sobre el español de México, UNAM, México, 1972, pp. 109-123; Perissinotto, "Hacia una fonética del español...", pp. 66 y ss. Por su parte Phillips, en relación con el español de Los Angeles, entre otros alófonos distingue [ŷ], [y], [j] (pocas veces), [0] (en contacto con $i$, a veces). No deja de llamar la atención la presencia de un alófono

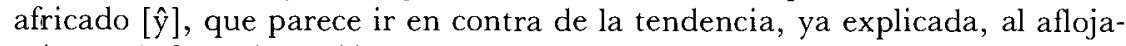
miento de la articulación. En nuestros materiales, sin embargo, también se documentó (en un informante y de manera esporádica) el alófono africado [ŷ]: la llave, proyecto > [laŷábe, proŷégto].

${ }^{28}$ Nuestros datos coinciden, en buena medida, con los de PHILLIPs para Los Angeles, quien asigna una frecuencia de $75 \%$ al alófono aspirado y $25 \%$ a la articulación consonántica, sin distinguir relajación intermedia ("The segmental phonology...', p. 78). 
ho, harđín, hénte, emerhénsja, lúxo, exémplo, manexándo, sexuntó].

El grupo de consonantes $/ b, d, g /$. Por lo general, el comportamiento de estos fonemas en Santa Barbara responde a lo que caracteriza a la mayoría de los dialectos hispánicos respecto a su articulación fricativa en toda posición, excepto tras pausa o nasal ( $\mathrm{y}$ a veces tras otras consonantes como $/ \mathrm{r} / \mathrm{o} / \mathrm{l} /$ ), en cuyo caso son oclusivas $^{29}$. Lo que este grupo de consonantes presenta como peculiar es, por una parte, de nueva cuenta, la relajación con que se pronuncian, de manera predominante cuando aparecen en posición intervocálica y, por otra, la algo más que esporádica articulación labiodental de /b/ > [v] en diversas posiciones. Por lo que corresponde al primero de los fenómenos, debe señalarse que en este dialecto, como en otros donde también se produce, la relajación, cuantitativa y cualitativamente, no es la misma para los tres fonemas. Es la /d/ la que se relaja más notable y frecuentemente; le sigue la /b/ y, como consonante del grupo más conservada, la $/ \mathrm{g} /$. Para las tres pueden distinguirse tres alófonos o realizaciones: la articulación plena [ $\hbar, \mathrm{d}, \mathrm{g}]$, normalmente fricativas, la pronunciación debilitada $[\boldsymbol{b}, \mathrm{a}, \mathrm{g}]$ y su desaparición o cero fonético $[\emptyset]$. El resumen de frecuencias puede expresarse así:

\begin{tabular}{lccc}
\hline & $-d-$ & $-b-$ & $-g-$ \\
\hline Conservación & $49 \%$ & $60 \%$ & $64 \%$ \\
Relajación & $40 \%$ & $40 \%$ & $32 \%$ \\
Pérdida & $11 \%$ & - & $4 \%$ \\
\hline
\end{tabular}

La pérdida total de /d/, como en otros dialectos, se da particularmente en la terminación -ado y va acompañada por una notable cerrazón de la vocal final: olvidado, empleado, encontrado > [olbiđáo, empljáọ, e $\eta$ kontráọ]; se encuentra también el fenómeno en otros contextos fónicos y en casos de fonética sintáctica: se dice, la dejó, donde, todavia perdido, morido (por muerto) > [seíse, làexó, ónde, tọatía, perđíọ, morío]. Los esporádicos casos de pérdida de /g/ o corresponden a un determinado entorno: agua, lagos, luego > [áwa, láos, lwéo]. Ejemplos de las demás relajaciones: nacidos, todos, lado, le dije, propiedades, trabajé, hablaba, agarraba, sabe, sabiamos,

${ }^{29}$ Aunque algún informante articuló de manera evidentemente esporádica la $-b$ - intervocálica como oclusiva $[\mathrm{b}]$ : he vivido $>$ [ébibido]. 


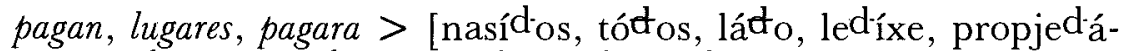

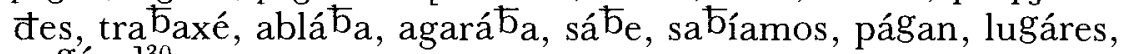
pagára] ${ }^{30}$.

Con referencia todavía a fenómenos de relajación en este grupo, es necesario dejar consignado que la /d/ en posición final de palabra tiende a perderse totalmente o a articularse con casi nula tensión. El análisis de nuestras cintas nos señala que en un $65 \%$ de ocasiones la - $d$ o se pierde o se debilita muy notablemente; sólo en un 35 por ciento de casos se conserva, no muy tensa. Ejemplos: Navidad, usted, propiedad, responsabilidad, realidad, comunidad > [nabiđá, usté, propjeđá, responsabiliđá, realiđá, komuniđá].

La articulación labiodental $[v]$ de / $/ b /$. Si bien la articulación labiodental de la /b/ se ha venido documentando desde hace mucho, tal alófono se ha explicado casi siempre como resultado del afán, por parte de maestros, de distinguir fonéticamente entre las grafías $b$ y $v$. A esta consideración hay que añadir la dimensión sociolingüística que indica un marcado aumento del porcentaje de realizaciones labiodentales según aumenta el nivel socioeconómico del hablante ${ }^{31}$. La labiodental es percibida, además, como rasgo de prestigio que se relaciona con la pronunciación culta. Parece fuera de duda que la documentación, mucho más que esporádica de este rasgo en el dialecto que estudiamos, apunta al bilingüismo de los informantes como determinante de esta pronunciación. Nuestros datos revelan que la articulación labiodental está vinculada no sólo a la grafía, sino a la presencia de una [v] en inglés, lengua que distingue fonológicamente entre la /b/ y la /v/ (bile/vi$l e$; saber/saver forman pares mínimos en inglés). Si por un lado nuestros materiales documentan un número elevado de [v] para $v$ gráfica en español o en cognados ingleses (valor, grave, invite), los casos de "ultracorrección" (articular una labiodental donde la grafía sugeriría la bilabial) son bastante raros: volver $>$ [volvér], pero no bicicleta $>$ [*visikléta]. Entre los abundantes ejemplos de [v] apuntamos: vino, si voy, viajes, ha vivido, valiente, los vicios, qué vida > [víno, sivói, vjáxes, avivíđo, valjénte, lozvísjos, kévíđa]. En términos de la distribución alofónica, hay que señalar que la labiodentalización de la $v$ gráfica, si llegara a generalizarse, conduciría a una nueva alineación del alófono oclusivo [b] frente a

${ }^{30}$ Phillips, para el español de Los Angeles, anota sólo una esporádica pérdida o debilitamiento de $-d$ - y - $g$ - intervocálicas (ibid., p. 76).

${ }^{31}$ Cf., por ejemplo, Peter Boyd-Bowman, El habla de Guanajuato, UNAM, México, 1960, pp. 54-55. 
los fricativos [ $\mathrm{b}]$ y [v]; en el sistema resultante la [v] fricativa ocurriría en posición inicial absoluta y tras lateral y líquida, contextos que el sistema actual asigna al alófono oclusivo. A propósito del afán distinguidor de algunos pedagogos, hay que recordar aquí que los informantes de nuestra muestra son, en la mayoría, personas bilingües de escolaridad principalmente norteamericana, de manera que la distinción entre $b$ y $v$ se ve doblemente reforzada. La distinción entre /b/ y /v/, necesaria en inglés, es transferida también al español ${ }^{32}$.

Otros hechos fonéticos esporádicos. Aunque no con la regularidad de los demás fenómenos, pueden consignarse, en lo concerniente a la articulación de las consonantes, ciertos rasgos que se escucharon en algunos sujetos: 1) en tres de los informantes pudimos documentar la despalatalización del fonema $/ \tilde{n} /$, que resulta en una [n] alveolar seguida por un elemento palatal semiconsonántico: niña, niños, compañía > [nínja, nínjos, companía], esta última ya lexicalizada en el habla de muchos hablantes, posiblemente por analogía con el inglés company; 2) más frecuente (en seis sujetos), aunque sin ser sistemática, fue la aspiración de /s/ tanto implosiva cuanto explosiva, y en especial en nosotros [nohótros] ${ }^{33}$; otros casos: digamos en..., otras actividades, las casas $>$ [digámohen, ótrahagtitiơáđes, lahkásas]; 3) en dos conversaciones, los hablantes articularon como velar fricativa la $f$ - seguida de $[w]$ : fui, se fue $>$ $\left[\right.$ [xwí, sexwé] ${ }^{34}$; 4) algunas $l$ retroflejas, cuya articulación se debe sin duda a la interferencia con la articulación inglesa de la /1/ en posición final de sílaba: español, general > [españól, xenerál] ; 5) en algunas ocasiones se escuchó una $c h$ con elemento fricativo predominante: mucho, ocho, los chicanos > [mú'šo, ó'šo, los'sikános], o totalmente fricativa: mucho, hecho, leche $>$ [múso, éšo, léše ${ }^{35}$;

${ }^{32}$ Que el bilingüismo español-inglés es un factor que incide en la presencia y distribución de los alófonos de / $b /$ se ha apuntado para otras zonas. Para San Antonio, Texas, cf. Perissinotto, "Hacia una fonética... ", pp. 62-63. En un estudio reciente, PHILLIPS ("Influence of English /b/...") reporta un importante porcentaje de [v] en Los Angeles en diferentes posiciones y tipos de hablantes, sobre todo cuando sigue a una consonante, más en hombres que en mujeres y más frecuente en jóvenes y adultos que en ancianos.

${ }^{33}$ PHiluips, ("The segmental phonologhy...", p. 77) hace alusión precisamente a la articulación [nohótros] entre las aspiraciones o elisiones registradas en el español de Los Angeles.

${ }^{34}$ Articulaciones también registradas por PHILlips en Los Angeles (loc. cit.).

${ }^{35}$ Aunque también se dio algún caso de $c h$ en que predominaba el elemento oclusivo: noche, derechito $>$ [nóŝe, dereŝíto]. La pérdida del elemento 
6) sólo en un sujeto se produjo, de manera esporádica, la sonorización de -s-: clase, cinco semanas $>$ [kláze, sínkozemánas $]^{36}$; 7) en varios informantes, al pronunciar los vocablos papá y mamá, se dio la elisión de la consonante inicial: [apá, amá] ${ }^{37}$.

\section{Observaciones gramaticales}

Si, en términos generales, la pronunciación del español en Santa Barbara puede caracterizarse como de consonantismo en cierto grado debilitado ${ }^{38}$ y en ello no parece producirse sino una continuidad del fenómeno evolutivo normal de la lengua española en particular y de las lenguas románicas en general ${ }^{39}$, por lo que toca a los rasgos morfosintácticos, quizá su principal peculiaridad sea el arcaísmo y ruralismo por una parte y, por otra, ciertas vacilaciones (en género, formas verbales, etcétera) que tal vez se deban a lo que podría denominarse ausencia, en la localidad, de una nor-

oclusivo está documentada como esporádica en PHiLLIPs, "The segmental phonologhy...", pp. 76-77).

${ }^{36}$ En ibid., p. 77 también se registra este fenómeno.

${ }^{37} \mathrm{Cf}$. ibid., pp. 89-90. A nuestro entender y a pesar de los casos de posible interferencia del sistema inglés, no se puede hablar, stricto sensu, de influencia fonológica. TsuzAKI, op. cit., pp. 46 ss., al clasificar la "influencia fonológica" del inglés en el español mexicano de Detroit, utiliza sólo ejemplos de vocablos ingleses, insertos en el léxico de este dialecto. Así habla de nuevos fonemas: / $\hat{y} /$ en /ýćlohyellow, $/ \mathrm{v} /$ en /bjurišóp/ beauty shop. . . ; de nuevas distribuciones: - $p$ en /pósap/ porrchop...; - $t$ en /klóset/ closet, - $k$ en /bisték/ beefsteak...; de nuevos grupos consonánticos: -ks en /bóks/box, sk- en /bói skáut/ boy scout, - ts en /bói iskáuts/ boy scouts, etcétera. Esta manera de enfocar el problema llevaría a incluir, en el español de la ciudad de México, por ejemplo, los fonemas $/ \mathrm{s} / \mathrm{y} / \hat{\mathrm{s}} / \mathrm{del}$ náhuatl por el hecho de que esos fonemas se dan en algunos vocablos que de esa lengua tiene el vocabulario de hoy (mixiote, quet$z a l$, por ejemplo). Creemos que para hablar de verdadera influencia sería necesario comprobar la existencia de nuevos fonemas, distribuciones, grupos, etcétera, en vocablos españoles y no en préstamos ingleses. Quizá una postura intermedia sea la de reconocer la existencia de estos sonidos ajenos a la estructura fonológica del español e insertarlos en ésta como fonemas de rendimiento funcional mínimo.

${ }^{38}$ Aunque conviene señalar que están ausentes, casi totalmente, rasgos que podrían ser típicos de hablas de consonantes relajadas, como la aspiración o pérdida de $-s$, la confusión de líquidas, la velarización de - $n$, etcétera.

39 Véase, para el desarrollo de esta idea, la ponencia de Ángel RosenBLAT, "Contactos interlingüísticos en el mundo hispánico: el español y las lenguas indígenas de América", en CH(2), pp. 109-154. 
ma lingüística española culta. Con ello queremos decir que en la gramática, mejor que en la fonética, se puede observar el carácter predominantemente popular y rural tanto de las bases históricas del dialecto (primeras décadas de este siglo, con inmigrantes casi todos campesinos) cuanto de la continua, hasta hoy, corriente migratoria que, socioculturalmente, tiene las mismas características del elemento básico. Podría pensarse que los recién llegados, los mexicanos que a diario se incorporan en las diversas comunidades hispanohablantes de California deberían influir en cierta estandarización del dialecto, en alguna igualación con dialectos predominantes en México (el de la capital, por ejemplo); sin embargo, parece más bien que son los nuevos inmigrantes, que en su mayoría llevan además el propio dialecto rural, los que se incorporan al tipo de habla que encuentran al llegar, lo cual, por otra parte, es absolutamente normal si se acepta, como se postula para Santa Barbara, la existencia de un verdadero dialecto establecido y no sólo el conglomerado de un determinado número de hablantes bilingües.

Con referencia a categorías nominales, distinguimos primeramente algunas vacilaciones en cuanto al género. Se producen sobre todo en sustantivos en $-a$ y en $-\ell$. Como se ha observado para otros dialectos en los Estados Unidos, varios sustantivos masculinos en - $a$ (la mayoría de origen griego) se vuelven femeninos por analogía y nivelación con los mayoritarios femeninos en - $a$ : la idioma, idioma distinta (en varios informantes), la diploma, la clima, unas poemas, muchísimas problemas, la panorama. Más explicable y muy extendido resulta el uso del artículo femenino ante $a$ tónica: la agua, la área, la águila. Se registran también casos, quizá menos frecuentes, pero no menos interesantes, de femeninos en - $a$ que se vuelven masculinos: los memorias, el oficina, el policía (como institución), todo su escuela, ningún persona ${ }^{40}$. Muy frecuente es el anteponer artículo masculino o modificar sustantivos femeninos en $-\ell$ con adjetivo masculino: $e l$ base, muchos bases, el costumbre, $e l$ frase, otro vacante, poquitos gentes, el mayor parte. Otras alternancias de género: las doctores, los tradiciones, la primer semestre ${ }^{41}$.

Por lo que al número corresponde, sólo registramos algunas omisiones del morfema del plural. Esto es particularmente frecuen-

${ }^{40}$ Particularmente notable y anormal fue, en un sujeto, el masculino los casas.

${ }^{41}$ Puede producirse, además de la vacilación en el gramema, también una confusión léxica: un ramo por una rama (de árbol), por ejemplo. 
te cuando el sustantivo año va después de un numeral cardinal: 21 año, 35 año ${ }^{42}$. El fenómeno también se produce en otros contextos: unos restorán.

Otros fenómenos relacionados con categorías nominales apuntan a un orden sintáctico poco usual en español y a la influencia del inglés; en los informantes que produjeron estos sintagmas se registra una notable preferencia por el inglés: el chicano grupo, muy chiquito pueblo. Gentilicios del tipo puertorricano y costarricano, así como la marcada tendencia a construir fechas y números a la inglesa revelan la interferencia: Naci en 1943 se convierte en ... diecinuevecuarenta y tres, el número 5367 se lee cincuenta y tres-sesenta y siete ${ }^{43}$.

Varios rasgos morfológicos pueden señalarse para la categoría verbal. Quizá entre los más relevantes, por su alta frecuencia entre los sujetos en cuya habla se basan estas notas, se hallen el copretérito (o imperfecto) en la primera persona de plural con desinencia -ábanos, -íanos, en sustitución de las formas generales -ábamos, -iamos. Se trata de una forma que, en el español mexicano, se da sólo en hablas rurales y ahora, nos parece, en vía de desaparición hasta en esos registros. Algunos ejemplos: estábanos (muy frecuente), andábanos, transportábanos, ibanos, teníanos, hacianos, vivianos. El fenómeno se produce aun con el verbo ser: éranos ${ }^{44}$. Otra formación peculiar del copretérito aparece en verbos como decir, venir, tener, que presentan una $i$ en su raíz: dician, vivia, tinía. En decir y venir parece claro que influyen las formas con $i$ del paradigma (dije, diré, diría, di...), explicación que no sirve para tener, a no ser que sea el diptongo ie de tienes, tiene el que, con su semiconsonante palatal, opere en la analogía ${ }^{45}$. Para terminar con el copretérito, consignamos las formas tenimos (por teníamos), ría (por reía), pudia (por podía), escuchadas en uno de los informantes. Otro rasgo, dentro de la categoría verbal, muy frecuente y de fuerte carácter rural es la segunda persona del singular en -a(s)tes, -i(s)tes: casates, hicistes, zafates, dijistes, etc. ${ }^{46}$. Se registraron también algu-

${ }^{42}$ Aunque también se documentó la falta de gramema en algunos adjetivos antepuestos: último años.

${ }^{43}$ Varios fenómenos semejantes son señalados por FrrTZ Hensey, "Toward a grammatical analysis of Southwest Spanish", en BOwen y ORNSTEIN, Studies in Southwest Spanish, pp. 32 ss., en relación con el español de El Paso, Texas: el/la clima, el/la calle, mejor persona/persona mejor, todos los chicano(s), etcétera.

${ }^{44}$ Huelga decir que la analogía operante es con el pronombre objeto nos para primera persona plural.

${ }^{45} \mathrm{El}$ mismo fenómeno se da también con otros verbos en el pretérito: sirvi, sigui.

${ }^{46}$ Las formas de segunda persona no aparecen a menudo en una entre- 
nos ruralismos comunes a otras hablas hispánicas: salemos por salimos, semos por somos, haigan por hayan, queren por quieren, todos ellos muy repetidos en las cintas. Se documentaron otras formas que, aunque esporádicas, apuntan a alteraciones notables del sistema verbal y, lo que es más, a un dialecto en que la analogía opera impunemente por la falta de una norma culta consciente entre los hablantes: se escasó por escaseó, ladrean por ladran, morido por muerto, atrayera por atrajera, ofreso por ofrezco, póneme por ponme, participiaron, dijiera, etcétera.

Con la sintaxis verbal más que con su morfología tienen que ver otros casos interesantes, particularmente el uso de la pasiva en nacer (fui nacido, me naci, es nacido). Se sabe que la pasiva inglesa queda reflejada en un uso más frecuente de esta construcción del que es habitual en español. Sin embargo, destacamos el caso de nacer por su carácter instransitivo ${ }^{47}$, y otros como se enseñó por aprendió. En el área de la semántica verbal incide la confusión o alternancia en el uso de los verbos ser y estar. Puede influir en ello, tratándose de hablantes bilingües, el hecho de que las significaciones que en español se distribuyen entre estos verbos, en inglés se concentran todas en to be. En una de las cintas analizadas apareció la expresión "no está muy hábil", , donde el español general usaría ser; en otra, se produce el fenómeno contrario: "es muerto" por está muerto ${ }^{48}$.

Aunque un estudio más detallado podría descubrir interesantes casos de vacilaciones en la consecutio temporum, baste señalar tres ejemplos: "creí que no me fuera a gustar" (subjuntivo por indicativo) ${ }^{49}$, "diez años antes que entramos" (indicativo por subjuntivo), "yo sé que sí pudiera" (subjuntivo por pospretérito).

Algunas observaciones sobre otras categorías gramaticales: se registró varias veces la supresión de un pronombre obligatorio, como en interesó por se interesó, gradué, por me gradué (en varios in-

vista a menos que ésta reproduzca en la conversación otra más íntima. Aún así se registró un número suficiente de casos que permite suponer que el fenómeno es bastante frecuente. Lo que sorprende no es tanto la $-s$ analógica (que se oye en hablas populares y medias de México y de otros países) cuando la pérdida de la -s en -aste, -iste $>$-ate(s), ite(s).

${ }^{47}$ No creemos que el uso medieval y clásico de nacerse sea mejor explicación que la presencia del inglés $I$ was born.

${ }^{48}$ Hensey, op. cit., pp. 32 y ss. hace también referencia, para el español de El Paso, a este tipo de neutralización entre ser y estar.

${ }^{49}$ Quizá se trate de una contaminación con "no creí que me fuera a gustar". 
formantes), quedé, por me quede $e^{50}$. Los ruralismos quen por quien y naiden por nadie se repiten con frecuencia ${ }^{51}$.

Entre los adverbios se oyeron también varios que son propios de hablas rurales: ansi, ansina, muncho, dispués, ahoy. Así como comparativos y superlativos dobles: muy grandísimo, más mejor. Alguna vez se pluralizó bastante: bastantes duros ${ }^{52}$.

$\mathrm{Si}$ en cualquier dialecto del español se dan imprecisiones en el uso de ciertas preposiciones, no es extraño que en el español de Santa Barbara se produzcan peculiares construcciones, como por ejemplo: por en lugar de para, sustitución repetida en varios sujetos ("trabaja por ellos", "trabaja por el teléfono", 'para la compañía de teléfonos"); supresión de de ("cobraba más renta que yo pensaba"); por dentro de en sustitución de atrás de ("están por dentro de un vidrio"); en veces por a veces; entre mí por para mí responsable por en lugar de responsable de; junto con o junto de por junto a ("no estoy junto con muchos japoneses", “ junto de mi familia"); depende en por depende de, etcétera ${ }^{53}$.

Las peculiaridades en el uso de las conjunciones son menos abundantes. Debe señalarse empero que en varios sujetos aunque es anque y en algún otro se dio un caso de pero por sino: "no sólo en España pero en otras partes" 54 .

No son pocos los casos en que, tratándose de sintagmas, puede dudarse si caben en el apartado de gramática o si mejor corresponde enlistarlos en el léxico. Tal vez pueda aplicarse esto a expresiones, relativamente frecuentes en nuestros informantes, del tipo: "agarró de enseñarse" ('se propuso'), "'tiene piensos de regresar' ('intenciones'), 'ir, mover o volver para (pa') atrás", muy común en nuestros informantes ('regresar'), "16 años pasados",

${ }^{50}$ Sin duda por interferencia con los enunciados ingleses $I$ graduated, I stayed. Hensey, loe. cit., transcribe ejemplos del tipo se divierte/divierte.

${ }^{51}$ Los relativos no mostraron particularidades aunque, en un sujeto culto se registró la siguiente construcción: "departamento cuyo recibe...", quizá efecto de cierto rebuscamiento en la expresión.

${ }^{52}$ Hay también otro tipo de formaciones adverbiales que, quizá, puedan tener su explicación como una creación individual en el momento de la charla: gramáticamente por gramaticalmente, sea por caso.

${ }^{53}$ Más anómalo aún resulta el pronombre nominativo yo precedido de la preposición ("historia de yo"), aunque se ha señalado para otros dialectos hispánicos; cf. Charles KanY, Sintaxis hispanoamericana, Gredos, Madrid, 1969, pp. 129 ss.

${ }^{54}$ Uso, aunque no frecuente hoy, sí documentado en los clásicos; cf. $\mathrm{S}_{\mathrm{A}}$ MUEl Gili Gaya, Curso superior de sintaxis española, Bibliograf, Barcelona, 1964, p. 282. 
('hace 16 años'), "dos meses para atrás" ('hace dos meses'), "entretener una conversación" ('sostener'), "paré de trabajar" ('dejé'), "reconocían al mismo lugar" ('volvían'), "escuela de máquina de escribir" ('academia comercial' o algo semejante), "tuvimos un buen tiempo" ('la pasamos bien', muy común), "levantar palabras" ('aprender, quedarse con'). Si bien algunas de estas expresiones podrían rastrearse hasta la época clásica, un buen número de ellas son producto de la interferencia con el inglés.

\section{Observaciones Léxicas}

Es evidente que la conversación espontánea, sobre todo cuando se trata, como en nuestro caso, de pocas horas y de corpus por tanto limitado, no es el mejor instrumento para conocer el léxico peculiar de un determinado dialecto, pues un cuestionario léxico bien preparado, sea por caso, funciona mucho mejor para este objeto. No queremos sin embargo dejar de consignar algunas voces que aparecieron en las cintas y que, a nuestro juicio, pueden considerarse peculiares.

Explicablemente la gran mayoría de los vocablos que pueden calificarse como de carácter no estándar, son anglicismos ${ }^{55}$, en los que se puede observar un diverso grado de hispanización (fonética y gramatical) o fenómenos de calcos semánticos: aplicación (solicitud), aplicar (solicitar), aseguranza (póliza de seguro), asistencia (ayuda), asociarse (juntarse, reunirse), atendencia (asistencia, presencia en una reunión), bloque (manzana, cuadra), bus o bos (autobús), dipo (estación, terminal de autobuses), carpeta o carpetera (alfombra), coger ('el español', tomar un curso de), chanza (oportunidad), expectancia (expectativa), guardiar (vigilar), letras (cartas), lonche (almuerzo) ${ }^{56}$, luz (semáforo), magacin (revista), mayoridad (mayoría), minoridades (minorías), organisizar (organizar), mover(se) (mudar[se], cambiar[se]), planeo (planeación), pompa (bomba [de gasolina o para inflar]), posición (puesto, cargo, empleo), portable (portátil), (el) principal (director de escuela primaria o secundaria), puchar (empujar), taxaciones (impuestos), telefón (teléfono),

${ }^{55}$ Obviamente no consideramos aquí los abundantes vocablos, sintagmas o textos extensos que los informantes dijeron en inglés e integrados en la cadena hablada por el cambio de código (code switching).

56 Voz de uso frecuente en México, sobre todo, pero no exclusivamente, en el norte. 
tr(a)inear (entrenar), $\operatorname{tr}(a)$ ineo (entrenamiento), troque(a) (camión de carga), vecinidad (vecindad, vecindario).

Otras voces no parecen explicables como anglicismos sino como arcaísmos, ruralismos, regionalismos o creaciones momentáneas y personales: agarrar vacaciones (tomar vacaciones), aprendista (aprendiz), cienes (cientos), conocencia (conocimiento), medecina (medicina), menear (manejar, conducir), mirar (ver, comprender) ${ }^{57}$, psicólica (psicóloga), pizcar (cosechar) ${ }^{58}$, resollar (respirar), resura (rasurada, afeitada).

Investigaciones futuras y más pormenorizadas revelarán, sin lugar a duda, que este dialecto comparte gran parte de los elementos léxicos señalados por varios autores como propios del castellano en California, como los verbos de influencia inglesa que señala Blanco: bicharse (desnudarse), bruchear (cepillar), cuquiar (cocinar), draivear (manejar, conducir), resignar (renunciar, dimitir), tritiar (convidar), entre muchos otros (pp. 505 ss.). Pero nuestras muestras léxicas sí parecen encajar dentro del esquema que ha propuesto Craddock para el español del suroeste en general: mexicanismos (manda, menudo), influencia léxica del inglés con o sin semejanza fonológica (curemos [we don't care], marqueta [market]), desplazamiento semántico (historia por cuento, realizar por darse cuenta de), conversión de sintagmas ingleses en construcciones adjetivales (camión de escuela, tiempo de escuela).

\section{CODE SWITCHING}

A juicio de la mayoría de los estudiosos, existe otro fenómeno lingüístico destacable en el español de los Estados Unidos, en especial en el californiano y el puertorriqueño; es éste el conocido con el nombre de cambio de código (code switching), que, a grandes rasgos, consiste en la alternancia de dos lenguas en el discurso. No se puede considerar precisamente como un préstamo, pues cada lengua se habla con su propia fonología y gramática. No se limita a una palabra individual, sino que con frecuencia involucra grupos sintácticos complejos, cuya comprensión presupone un grado

${ }^{57}$ En muchos sujetos se percibe la preferencia por el verbo mirar para abarcar un sector semántico que normalmente comparten varios verbos como ver, entender, concebir, comprender, etcétera.

${ }^{58}$ Este vocablo de origen náhuatl en México se emplea, por lo general, sólo en su forma sustantiva, pizca. 
de bilingüismo bastante avanzado por parte del interlocutor. Se trata además de un fenómeno cuyas ocurrencias precisas son, aparentemente, impredecibles.

Parece evidente que un requisito indispensable para que exista el cambio de código es un nivel avanzado de bilingüismo no sólo a nivel individual sino también social. De conformidad con los datos de Barnach-Calbó, tres cuartas partes de la población hispánica de los Estados Unidos es bilingüe en distinto grado; un $9.9 \%$ es monolingüe en español y un $13.2 \%$ lo es en inglés. El bilingüismo con preponderancia en español es mayor en jóvenes menores de 13 años y en adultos mayores de 45 . Entre estas edades se da lo contrario: bilingüismo con predominio del inglés. Es probable que la lealtad a la lengua materna sea más fuerte en la minoría hispánica que en ninguna otra.

Por lo que toca en particular a la comunidad hispánica de Santa Barbara, puede decirse que en su gran mayoría es bilingüe. A nuestro juicio se aplica aquí lo señalado por Rosaura Sánchez ${ }^{59}$ para todo el suroeste: la primera y segunda generaciones se encuentran frecuentemențe en situación diglósica si residen en un "barrio" (donde predominan los mexicanos). Para este segmento de la población el español es la lengua de la casa y el inglés es el estándar en la comunidad. La segunda y tercera generaciones, cuando residen en comunidades "integradas" (a la sociedad norteamericana), funcionan casi exclusivamente en inglés, incluso en casa, sobre todo cuando los padres se han educado en los Estados Unidos. Quizá, por lo contrario, no resulte aplicable a Santa Barbara lo anotado por George C. Barker ${ }^{60}$ para el bilingüismo en Tucson: los hispanos nacidos en los Estados Unidos hablan el dialecto español del sur de Arizona y un inglés subestándar; muchos inmigrantes, español estándar e inglés subestándar; las familias antiguas, español estándar, el dialecto del sur de Arizona e inglés estándar.

La alternancia de dos lenguas dentro de un mismo acto comunicativo es un aspecto que ha merecido la atención de algunos estudios en los últimos años. Si por un lado se había pensado que

59 Rosaura Sánchez, "Chicano bilingualism", en New directions in Chicano scholarship, Center for Chicano Studies, University of California, Santa Barbara, 1984, pp. 209-225.

${ }^{60}$ George C. Barker, Pachuco, an American-Spanish argot and its social functions in Tucson, Arizona, The University of Arizona Press, Tucson, 1974. Hay que señalar, sin embargo, que la descripción de este dialecto corresponde a una situación sociolingüística de hace más de 40 años. 
el cambio de código era un manifestación de deficiencia lingüística, las teorías más recientes sostienen que el cambio de código no obedece a reglas de competencia en una sola lengua sino que descansa en gran parte en el conocimiento de dos lenguas y requiere que se conforme a un conjunto de reglas que pueden llegar a ser muy específicas. También se ha dicho que el uso del inglés y el español en la misma cadena hablada es señal del desmembramiento de la comunidad lingüística. Los hablantes bilingües, sin embargo, han declarado que esa práctica forma parte íntegra de su identidad étnica y refleja el haber nacido en una comunidad en la que se emplean dos idiomas. En el plano puramente lingüístico no es peregrino pensar que el cambio de idiomas refleja una distribución complementaria de las dos lenguas. Este bilingüismo puede, como hemos visto, llevar a casos de interferencia entre las dos lenguas. El castellano, por ser lengua minoritaria y de menor prestigio en la mayor parte de las situaciones, es la lengua que más sufre en una situación de contacto.

Si un enunciado contiene segmentos de los dos sistemas lingüísticos, el hablante seguirá las reglas de pronunciación del sistema al que pertenece el segmento. Así que en una oración como Tengo que hacer mi homework (tarea), las palabras españolas se ajustan a la pronunciación española mientras que la inglesa sigue las reglas del inglés. Los códigos que cambian son, por consiguiente, los respectivos sistemas fonológicos. Si la pronunciación se ajustara a un solo sistema fonológico - y así sucede también- habría que hablar más bien de préstamo y no de cambio de código; tal sería el caso de un enunciado como No tengo dinero para pagar los hiles (bills, cuentas), donde bill(es), como tantos otros vocablos ingleses, ha sido incorporado al español y se ha ajustado a su fonología y morfología. Este primer tipo de cambio de código -donde la presencia de otra lengua se hace sentir intercalando lexemas aislados - es el más común y el más fácilmente documentable. Se suelen intercalar en la cadena hablada palabras inglesas que pertenecen a una serie o conjunto que el hablante asocia -inconscientemente- con los dominios del inglés: Lo vay a hacer el Tuesday, Thanksgiving siempre cae en November, No vi el stop sign y me dieron multa, $\mathrm{Ni}$ en preschool, ni en High School se aprende nada. Aunque no faltarían motivos para hablar de empobrecimiento léxico, creemos más bien que la baja frecuencia de ciertos vocablos, que en realidad son más que comunes en un país hispanohablante, se explica por el hecho de que la escolarización de muchos de nuestros informantes fue en un medio anglohablante, de manera tal 
que los cálculos aritméticos más elementales - y el deletreo de palabras, para mencionar otro ejemplo - se hace casi invariablemente en inglés.

Los estudios que tratan este tema señalan que si bien la alternancia entre las dos lenguas parece ocurrir al azar, un análisis más minucioso revela que existen patrones permitidos y aceptables así como secuencias restringidas o imposibles. Se ha hecho notar, por ejemplo, que mientras oraciones adverbiales del tipo Lo hizo slowly (lentamente), Vino early (temprano) son comunes en el habla de los bilingües, las interrogativas correspondientes $¿$ How lo hizo? (¿Cómo lo hizo?), ¿ When vino? (¿Cuándo vino?) no pueden ocurrir porque el inglés requiere el auxiliar do, did: When did he come?, How did he do it? ${ }^{61}$.

Cuando el enunciado en el que ocurre un cambio de código corresponde a estructuras similares en las dos lenguas - similares por lo menos al nivel de estructura de superficie- el hablante puede alternar libremente entre las dos lenguas, como en los ejemplos siguientes:

Tengo una niña que está en el programa bilingüe de preschool.

$H e$ is telling me que no le haga caso.

Estamos decididos a asking for a refund.

Estábamos jumping around.

En casos extremos de alternancia, ios interlocutores cambian de lengua varias veces en el mismo enunciado.

Y luego los teachers estaban hiding en el multi-purpose room sin darse cuenta de que we were right there. (Y luego los maestros se escondían en un salón sin darse cuenta de que estábamos allí mismo.)

El City Council votó against the project, pero no les hicieron caso and they went ahead with it, como si nada. (Los regentes votaron en contra del proyecto, pero no les hicieron caso y siguieron adelante como si nada.)

Oraciones de este tipo abundan en el discurso bilingüe y apuntan a la regla o requisito sociolingüístico que subyace en este dialecto: los interlocutores tienen que poseer un grado bastante eleva-

61 Rosaura Sánchez, "Our linguistic and social context", en Jon AmasTAE y Lucía Elías-Olivares, eds., Spanish in the United States, Cambridge, 1982, p. 42. 
do de bilingüismo y tienen que dominar las estructuras gramaticales de las dos lenguas para poderse comunicar eficazmente. Oraciones como las que presentamos no se podrían producir entre un bilingüe y un monolingüe en español (y menos con un anglohablante). Esto explica, creemos, la impresión que un hispanohablante monolingüe recibe del habla de muchos méxico-americanos: un español de código restringido, tanto en el dominio de las estructuras gramaticales como en la variedad y precisión del vocabulario. Pero visto desde otra perspectiva, esta "mezcla'" de lenguas constituye, en realidad, un sistema aparte; sistema compuesto de dos gramáticas que se complementan y apoyan mutuamente para formar una tercera.

\section{Conclusiones}

Si bien sería de esperar que la mayor parte de las variantes dialectales del español hablado en los Estados Unidos se conformen a la variedad estándar de la cual derivan, la ausencia de una norma constante y la migración han contribuido a que estos dialectos exhiban características propias y diferenciadoras. En términos generales notamos que al faltar una poderosa norma colectiva y centrípeta, cada variante da rienda suelta a aquellas tendencias que la norma generalmente controla o frena. Subrayamos asimismo que en el dialecto que describimos coexisten usos rurales y arcaicos al lado de tendencias innovadoras. Pero no hay que perder de vista que la convivencia de códigos distintos no es más que el reflejo lingüístico de una realidad social que estratifica a los hablantes y sus discursos. Cabe preguntarse, entonces, cuál de los cuatro tipos de bilingüismo señalados por Glyn Lewis ${ }^{62}$ se registran en la ciudad de Santa Barbara: estable, dinámico, transicional o residual. La sociolingüística moderna ha hecho notar que si el bilingüismo en un individuo es bastante común, las sociedades diglósicas no suelen gozar de una estabilidad lingüística duradera. Al otro extremo se ubican las sociedades donde sólo quedan vestigios, residuos, de un bilingüismo anterior inestable que culminó en el desplazamiento casi total de una de las lenguas. Tal es el caso de muchas lenguas amerindias y de las varias lenguas europeas de los emigrantes a los Estados Unidos que han ido su-

${ }^{62}$ Glyn Lewis, Multilingualism in the Soviet Union, Mouton, The Hague, 1972, p. 275. 
cumbiendo ante el inglés. En el caso del español en California y en Santa Barbara, consideramos que se trata más bien de bilingüismo dinámico o transicional. Si por un lado es cierto que el español está muy en uso y que los hispanohablantes están en vísperas de poder ejercer la influencia político-social que conlleva su mayoría numérica, no es menos cierto que las funciones y dominios de las dos lenguas favorecen al inglés. El español es lengua de los dominos del hogar, del barrio, de la iglesia, pero es todavía portador de los valores culturales de sus hablantes y símbolo de una identidad étnica que no se quiere borrar. El inglés, por otra parte, es el idioma de prestigio que ocupa los registros y dominios más altos en una sociedad asimilatoria que históricamente no ha manifestado tolerancia hacia el bilingüismo. El futuro del español en los Estados Unidos en general depende, en alto grado, de la política migratoria de este país y de la tenacidad de los hispanohablantes. El flujo continuo de inmigrantes de México y del resto de Hispanoamérica proporciona el elemento renovador y continuador del español; el lento y minúsculo esfuerzo de educar a los niños en escuelas bilingües representa la semilla que puede germinar en la penetración del español en dominios antes reservados para el inglés. Este estado movedizo y cambiante es el que hemos intentado documentar en la ciudad de Santa Barbara, California, en vísperas de la explosión demográfica y en un momento crítico de la política migratoria hacia los hispanohablantes.

José G. Moreno de Alba

Universidad Nacional Autónoma de México

Giorgio Perissinotto

Universidad de California, Santa Barbara 